Article

\title{
Animal Voices: Catherine Louisa Pirkis' The Experiences of Loveday Brooke, Lady Detective and the Crimes of Animality
}

\author{
Christopher Pittard \\ School of Social, Historical, and Literary Studies, University of Portsmouth, Portsmouth PO1 3AS, UK; \\ Christopher.Pittard@port.ac.uk
}

Received: 15 May 2018; Accepted: 14 June 2018; Published: 26 June 2018

check for updates

\begin{abstract}
While previous readings of Catherine Louisa Pirkis' series The Experiences of Loveday Brooke, Lady Detective (1894) have focused on Brooke's status as New Woman detective, this article considers the series in the context of Pirkis' own engagement with animal rights and anti-vivisection campaigns in the late nineteenth century. The discussion focuses on one Loveday Brooke story in particular, "The Murder at Troyte's Hill," arguing that Pirkis dramatises contemporary anti-vivisectionist rhetoric (that animal experimentation was not only scientifically flawed, but morally damaging, leading to human experimentation). Pirkis' fiction instead presents a number of contact zones in which human and animal identities are renegotiated, most significantly in the figure of Loveday Brooke herself. The article considers the representation of comparative philology in the story, as an emerging linguistic science which raised anxieties of cultural dissolution and which was often associated with the image of the vivisector. It concludes that the Pirkis stories demonstrate, anticipating Derrida, that to write of the animal in the nineteenth century is inevitably to write about crime, and vice versa; the animal is a perpetual presence in Victorian detective fiction.
\end{abstract}

Keywords: detective fiction; animal theory; anti-vivisection; comparative philology; popular fiction

\section{Introduction}

Victorian detective fiction presents the reader with a bestiary. From Poe's ourang-outang, it moves through the horses that pull Fergus Hume's hansom cab, Holmesian trained snakes, the curious incident of the dog in the night-time, and culminates at the cusp of the twentieth century with Arthur Conan Doyle's hound. It would be tempting to describe the animal as the spectre that haunts Victorian detective fiction, were it not that in such narratives the animal is often fully embodied; indeed, in many such narratives, it is reduced solely to body. The question of the animal body became particularly energised in the 1880s and 1890s with the growth of several anti-vivisection campaigns, a constituency which frequently overlapped with New Woman and emergent feminist movements, utilising a politics of identification in which the animal on the vivisection table was aligned with the woman as both medical and political subject. Anti-vivisection debate overlapped with detective fiction: Aesculapius Scalpel's [Edward Berdoe] St Bernard's: The Romance of a Medical Student (1887), a vivid condemnation of vivisectionist practice, featured a subplot about the tracking of a murderer (inevitably, an experimental physiologist); as I have argued elsewhere, detective serials such as Grant Allen's Hilda Wade (1899-1900) and L. T. Meade and Robert Eustace's Stories of the Sanctuary Club (1899) presented metaphorical parallels to anti-vivisectionist discourse (Pittard 2011, pp. 145-85). Yet while Allen and Meade's fiction avoids looking directly at the animal, for another practitioner of detective fiction the animal was a living concern, both in terms of literary production and political activism. This was Catherine Louisa Pirkis, a moderately successful author of romance fiction, who had turned to the 
increasingly popular genre of detective fiction for her last work, the serial The Experiences of Loveday Brooke, Lady Detective (1894).

Critical accounts of Loveday Brooke (such as those by Gavin (2010, 2012); Miller (2005), Hendrey-Seabrook (2008) and Skaris (2014)) usually focus on her status as a New Woman detective, and her position within a fin de siècle wave of female detectives including Allen's Lois Cayley (Miss Cayley's Adventures (1899)) and Hilda Wade, Meade and Eustace's Florence Cusack stories (1899-1900), and M. McDonnell Bodkin's Dora Myrl, The Lady Detective (1900). Here, I take a different approach by considering Pirkis through animality and the figure of the animal. Pirkis herself was what we might recognise as a writer activist on this question: with her husband, Fred E. Pirkis, she established the National Canine Defence League (now the Dogs' Trust) and was a committed anti-vivisectionist. I consider one episode in particular from The Experiences of Loveday Brooke, demonstrating how Pirkis uses the detective story genre to dramatise anti-vivisectionist arguments, and to draw on cultural anxieties about the rise of a comparative philology which not only paralleled vivisectionist practice but often sought to deprive the animal of language. Concluding with a comparison of Pirkis's writing with more recent theoretical approaches, I suggest that for Pirkis writing about the animal is already writing about crime. In summary, Pirkis's importance lies in making explicit the inherent connection between Victorian detective fiction-particularly where it deals with murder-and questions of animality.

\section{Introducing Loveday Brooke}

The Experiences of Loveday Brooke, Lady Detective was first published as a series in the Ludgate Monthly in 1893-1894, and published in volume form by Hutchinson in 1894. The titular Brooke, once a prosperous lady but obliged to work through losing her wealth through "a jerk of Fortune's wheel" (Pirkis 1894, p. 7), works as a professional private detective. She is often hired by the official police through the agency run by Ebenezer Dyer, although Dyer's role in the stories is limited to introducing the details of the case and providing an opportunity for Brooke to explain her reasoning at the end. Brooke's investigations are facilitated by her ability to work undercover and to gain the sympathy of those she investigates (a familiar trope of New Woman detective fiction, especially in George R. Sims' Dorcas Dene, Detective (1897), where Dene uses her previous experience as an actress to take on a variety of personae). As Dyer puts it in "The Redhill Sisterhood", "The idea seems gaining ground [sic] in many quarters that in cases of mere suspicion, women detectives are more satisfactory then men, for they are less likely to attract attention" (ibid., p. 96). The seven stories of the series cover a broad spectrum of crimes and settings, from jewel theft to murder, with Brooke investigating Millennial sects, religious sisterhoods, reports of ghost sightings, missing women, and international royal marriages.

Brooke was, inevitably, compared to Sherlock Holmes, a situation not entirely helped by Hutchinson advertising the Experiences as the cases of 'A Female Sherlock Holmes' ${ }^{1}$ or by Bernard Higham's illustrations occasionally paying tribute (to put it charitably) to Sidney Paget's work for Doyle (Higham's 'Loveday Explained the Whole Thing' clearly owes a considerable debt to Paget's 'We had the Carriage to Ourselves' and 'Holmes Gave Me a Sketch of Events' from 'The Boscombe Valley Mystery' and 'Silver Blaze' respectively). Most reviews were positive, although the Pall Mall Gazette's comparison of Brooke to Holmes was uncharitable:

The idea is the same as Mr Conan Doyle's, though no doubt prompted by an uneasy desire to avoid the charge of plagiarism, the author has made his [sic] central figure a lady detective; but somehow the interest is wanting. As moonlight is to sunlight, and as water is to wine, so are the methods of Loveday Brooke compared with those of Sherlock Holmes. The fact is,

1 See, for example, London Evening Standard, 26 April 1894, p. 8; the phrase was taken from the opening sentence of the review in the Glasgow Herald, 22 March 1894, p. 9. For reviews reading Pirkis in relation to Doyle, see 'Fiction', Speaker 7 April 1894, p. 396; 'Literary Notices', Liverpool Mercury, 4 April 1894, p. 7; 'Literature: New Books and Editions', Leeds Mercury 4 April 1894, p. 3; 'Novels', Saturday Review 5 May 1894, p. 477; Surrey Mirror 12 May 1894, p. 5; 'Literary Notes,' Sheffield Independent 11 April 1894, p. 2; Glasgow Herald 11 May 1893, p. 10. 
we get wearied with these stories ... . [t] he recipe is invariable: avoid the obvious criminal: connect your case if possible with some absolutely irrelevant advertisement read by chance in the morning paper: score off everyone all round, but remember last of all that it is possible even for an amateur detective to be a bore (Anonymous 1894a, p. 4).

The Pall Mall Gazette's confusion over Pirkis's gender was a recurrent theme of reviews. The Liverpool Mercury ascribed the Experiences to 'Mr Parkes' (Anonymous 1894b, p. 7) and the Dundee Courier and Argus to 'Mr Perkis' (Anonymous 1894c, p. 4). The Speaker did slightly better in getting Pirkis's surname correct, but still insisted that the author was male. The recurrent failure to recognize Pirkis as a female writer may be the cause of one of the most bizarre media appearances of Loveday Brooke, when the press reported on the opening of the new premises of the Women Writers Club at Norfolk Street, on 18 May 1894. The new rooms were opened by Princess Christian, witnessed by literary celebrities including Eliza Lynn Linton, Mrs. Humphry Ward, Israel Zangwill, and Thomas Hardy. The ceremony ended with a presentation in which 'the Lady Detective Loveday Brooke presented the Princess with the published volume of her experiences, which was graciously accepted' (Anonymous 1894d, p. 5). The presentation at the Women Writers Club had, of course, been made by Pirkis (as correctly reported in other newspapers), but in many accounts Loveday Brooke herself had rubbed shoulders with Thomas Hardy.

Comparisons of Brooke to Holmes occasionally noted the contrasts between the two in terms of gendered epistemologies. The Aberdeen Free Press review of 9 April 1894 was typical:

[Brooke] is made to solve the most intricate crimes with an ease and rapidity that would not have disagreed the inimitable Holmes himself. It is this apparent ease that marks the difference in the methods of the two. There is in the case of the lady detective a lack of the same keen deductive reasoning that marked the unrivalled methods of Conan Doyle's hero, where one link naturally and incontrovertibly followed the other. It may have seemed in the eyes of the author the prerogative of a woman, but there is in the experiences of Loveday Brooke more guess work-invariably successful—and her premises are not in every case strong enough to warrant the conclusions drawn (p. 3).

The claim that Holmes' method was 'naturally and incontrovertibly' logical is more ideological than factual, but even accepting the Holmesian claim to deductive rationality, there are two points here. Firstly, Loveday Brooke is aligned with a lack of rationality that is not only feminine, but also animalistic, in the Cartesian tradition that sees reason as the absolute division between human and nonhuman animals. As Carrie Rohman argues, fin de siècle and modernist literary treatments of animality often focused on this rationalist faultline, in the vivisector's "policing [of] the boundaries of rationalist humanism" (Rohman 2009, p. 70) in H. G. Wells' The Island of Dr Moreau (1896), to what Rohman terms animal 'anti-epistemology' in D. H. Lawrence, "a kind of knowledge that operates outside the constraints of language: they [animals] 'know' without reasoning, questioning, or wondering. Theirs is a presence that mocks the logic of Cartesian self-consciousness and power" (ibid., p. 132). Pirkis does not go as far as Lawrence in establishing an animal anti-epistemology, but my point here is that Brooke's apparent failure to emulate Holmesian rationalism can also be read more positively as congruent with the stories' thematisation of animality, including in the character of Brooke herself. Secondly, on a related note, my claim here is that the Loveday Brooke stories' reluctance to provide a wholly deductive paradigm may also be read as clearing space in order to focus on the ethical contexts of the cases Brooke investigates. In this regard, the closest Brooke gets to Sherlock Holmes is in Holmes' comments at the end of 'The Creeping Man' (1923) on the morality of Presbury's experiments with monkey serum: "When one tries to rise above Nature one is liable to fall below it. The highest type of man may revert to the animal if he leaves the straight road of destiny" (Doyle 1951, p. 183). It is to a similar narrative of animal experimentation in the Brooke stories, "The Murder at Troyte's Hill', that I now turn. 


\section{Animals, Detectives, Vivisectionists}

Given Pirkis' activism, it is unsurprising that animals abound in The Experiences of Loveday Brooke. There are numerous horses and ponies, cattle at market (Pirkis 1894, p. 32), and a donkey belonging to a religious sisterhood (ibid., p. 98). In the final story, 'Missing!', Loveday is suspicious of a woman whom she categorises as belonging to the 'Cat-tribe' of 'the velvet paw and the hidden claw' (ibid., p. 288). In the same story, treatment of animals is used as a moral barometer, when a young woman breaks off her engagement because she saw her fiancé 'cruelly thrashing one of his setters' (ibid., p. 290), and a $\operatorname{dog}$ fulfils a crucial detective function in finding a body. However, the episode which most explicitly addresses the question of the animal is the second of Brooke's adventures, 'The Murder at Troyte's Hill.' Loveday is employed by the Cumberland police to investigate the murder of Sandy Henderson, the lodge keeper to a philologist called Craven. Loveday goes undercover as an amanuensis for Craven's eight volume masterwork on philology, in which he is struggling with the problem of what he calls the six or seven 'fundamental sounds' of language, and in particular the question of how "is it possible to get a notion of a sound of agony that is not in part a sound of terror? Or a sound of surprise that is not in part a sound of either joy or sorrow?" (ibid., p. 77). Craven's eccentric work habits are tolerated by the household, including Craven's wife, his son Harry and daughter Nina. The dissolute Harry is the prime suspect, having argued with Sandy and threatened him with a hunting crop shortly before the murder; his situation is not helped by excusing himself from the inquest on the grounds of typhoid fever, confining himself to an isolated sick-room in the house. Nina, distressed by the murder, leaves for Newcastle. Loveday's investigations turn up odd clues, most notably the corpse of a black retriever hidden in the grounds of the house, and the police are baffled by Loveday's interest in the movements of a shipping passenger, Harold Cousins, in London. Eventually, all is revealed: Harry, believed to be guilty of the murder by his mother, escapes the country by boat from London under the name of Cousins (Loveday having noticed the family's interest in the name in the list of passengers in the morning newspaper). Nina, meanwhile, secretly returned from Newcastle to take Harry's place in the darkened sick-room. But Harry turns out to not be the murderer; the real villain is Craven, who killed his dog, Captain, as part of his philological research into the fundamental sounds of speech. Sandy encountered Craven killing the dog, and at that point Craven kills Sandy, the murder serving a double purpose as both a linguistic experiment to observe the death cries of Sandy and to end Sandy's blackmail of Craven, since Sandy knew of Craven's previous disreputable marriage to a barmaid in Oxford.

Elizabeth Carolyn Miller reads the Nina/Harry cross-dressing subplot of 'The Murder at Troyte's Hill' as embodying a blind spot of 1890s male detectives, unable to identify acts of passing gender or race (most famously, of course, Sherlock Holmes in 'A Scandal in Bohemia' (1891) (Miller 2005, p. 60). I suggest, however, that the boundary most suggestively crossed in the story is not one of gender, but of species, and in this episode Pirkis dramatises two of the most influential strands in anti-vivisectionist rhetoric of the fin de siècle. Pirkis herself was a committed anti-vivisectionist, dedicating her novel $A$ Dateless Bargain to the prominent anti-vivisection campaigner Frances Power Cobbe, "Whose noble advocacy of the rights of animals has lighted a fire of indignation in England against scientific cruelty which, by the grace of god, will never be put out" (Pirkis 1887, p. v). This is rather odd phrasing: if the 'fire of indignation' is never to be put out, does this also suggest that the scientific cruelty which feeds it is also permanent? One such example of this scientific cruelty occurs in 'Troyte's Hill', with the experiment Craven conducts on Captain:

I had been trying all day to assimilate a dog's yelp of pain to a human groan, and I couldn't do it. The idea haunted me-followed me about wherever I went. If they were both elemental sounds, they must have something in common, but the link between them I could not find; then it occurred to me, would a well-bred, well-trained dog like my Captain ... at the moment of death give an unmitigated currish yelp; would there not be something of a human note in his death-cry? The thing was worth putting to the test. If I could hand down in my treatise a fragment of fact on the matter, it would be worth a dozen dogs' lives (Pirkis 1894, p. 87). 
That night, Craven attacks Captain with a hammer, but the experiment proves worthless: "Why, he gave one loud, long, hideous yelp, just as if he had been a common cur" (ibid., p. 87). Craven's experiment relies for its utility on Captain acting like a human, making a human noise-or, more precisely, a noise with a trace of the human in it-as a result of being "well trained and well bred" (ibid., p. 87). Craven's experimental philology becomes a parody of Darwin's attention to animal communication (in particular emotions of fear and rage), and the problem of the interpretation of vocal sounds, in The Expression of Emotions in Man and Animals (1872):

The cause of widely different sounds being uttered under different emotions and sensations is a very obscure subject. Nor does the rule always hold good that there is any marked difference. For instance with the dog, the bark of anger and that of joy do not differ much, though they can be distinguished. It is not probable that any precise explanation of the cause or source of each particular sound, under different states of the mind, will ever be given. We know that some animals, after being domesticated, have acquired the habit of uttering sounds which were not natural to them. Thus domestic dogs, and even tamed jackals, have learnt to bark, which is a noise not proper to any species of the genus. (Darwin 2009, p. 86).

Craven takes up Darwin's challenge to distinguish the different sounds of the bark, but at the same time Darwin's commentary allows us to note the paradoxical nature of Craven's enquiry; his attempt to derive the fundamental sounds of voice depends on the vocality of apparently trained animals, who have "acquired the habit of uttering sounds which were not natural to them."

Craven's experiment follows one of the main strands of anti-vivisectionist argument of the 1880s and 1890s; that vivisection was at best epistemologically questionable, at worst scientifically useless. In 1891, for instance, the physician Elizabeth Blackwell had argued that while physiological parallels may be found between human and non-human animals, "Nowhere is there identity of structure or function" (Blackwell 1891, p. 2), rendering the results of any vivisectionist experiments worthless when transferred to human subjects. Blackwell took the paradigmatic vivisectionist animal-the dog-as her example: "the differences are so great, their whole attitude towards external life is so different, that they truly be said to live in a different world from ours" (Blackwell 1891, p. 3). Craven's explorations, like vivisection, depend on a paradoxical formulation whereby animals are simultaneously the same as humans (so that experiments on them will have scientific validity) and yet different (which justifies their status as objects to be experimented upon). But Craven makes a number of category errors that doom his project from the outset, the first of which is his belief that an animal can be raised to the status of human through training and breeding. There is a sense in which Craven's project here anticipates the linguistic conceptions of training outlined by Vicki Hearne and Paul Patton, in which training gives animals "tools for entering a relationship within which they can be said to speak, not merely to react" (Weil 2012, p. 10), activating animal areas of perceptual expertise not available to the human. Yet Craven's vivisectionist investment in human exceptionalism means that he falls short of the realization that, in Kari Weil's terms, "Training, like language, compels me [the human] to acknowledge that there is another phenomenal world, or Umwelt ... even as it reveals that our worlds (and our means of expressing them) are not commensurate" (ibid., p. 11). As Donna Haraway argues, animal training is not a hierarchy or monolithic relationship of power, but rather an intersubjective contact zone of human/animal entanglement in which "the human must respond to the authority of the dog's actual performance" (Haraway 2008, p. 221). Likewise, the play aspect of training in this contact zone is "the practice that makes us new, that makes us into something that is neither one nor two, that brings us into the open where purposes and functions are given a rest" (Haraway 2008, p. 237). Craven's error is to assume that training only modifies the animal, and to rely on the stable categories of 'human' and 'animal' destabilised by this contact zone. Yet the universe of the Loveday Brooke stories is not so anthropocentrically neat; Craven himself refers to Sandy as "that other brute" (Pirkis 1894, p. 93) (in comparison to Captain), while his housemaid is called Moggie (in the Victorian usage as dialect for calf, rather than cat), and Brooke herself (as argued below) is frequently conceived of as animalistic. 
The second strand of anti-vivisectionist argument was moral; that vivisection not only dulled the moral sense in practitioners (and Pirkis naming her proto-vivisectionist Craven is telling), but that combined with its scientific shortcomings, it would inevitably lead to experimentation on humans. This, in turn, led to the close association of the multiple (and often competing) anti-vivisection movements with an emergent feminist politics, and a politics of identification filtered through class, but primarily through gender: as Coral Lansbury and others have noted, the animal on the operating table became associated with the body of the woman (Lansbury 1985, p. x) and (less frequently) of the working class (as one anti-vivisectionist pamphlet claimed, in Germany 'they have a name for hospital patients which signifies 'beasts for research' (Versuchthiere)' (Anonymous n.d., p. 2)). Pirkis shows the trajectory clearly; immediately after killing Captain, Craven conducts the same experiment on the working class Sandy, with similarly futile results: Sandy "falls back without a sound" (Pirkis 1894, p. 87). As Craven confesses to Loveday, he completes the anti-vivisectionist trajectory by realising that a woman's cry might be the best subject of all:

I wonder what sort of sound you would make if I were to give you a little tap just there.' Here he lightly touched her forehead with the hammer. 'Elemental, of course, it would be ... ' [ ... ] 'It has only this moment occurred to me,' he said, now with his lips close to Loveday's ear, 'that a woman, in her death agony, would be much more likely to give utterance to an elemental sound than a man (ibid., pp. 89-90).

It is at this point that the police intervene before Craven can complete the experiment. This scene, illustrated by Higham, became the paradigmatic image of Brooke, chosen as the frontispiece for the 1894 volume republication.

The trajectory from animals to women as experimental subjects, made explicit in the story's final scenes, is earlier implicit in the series' alignment of Loveday Brooke with the animal. Loveday's animalistic nature is more subtly introduced to us in the first story, 'The Black Bag Left on a Doorstep': she "could best be described in a series of negations. She was not tall, she was not short; she was not dark, she was not fair; she was neither handsome nor ugly. Her features were altogether nondescript" (ibid., p. 6). As Therie Hendrey-Seabrook notes, even the surname Brooke recalls the verb to brook, "usually deployed in a negative mode" (Hendrey-Seabrook 2008, p. 77). But to be described by a series of negatives is precisely to occupy the position of the animal in Western philosophy. For Descartes, the animal is without response, soul or language; for Martin Heidegger, the animal is without a sense of the world as such, and so on. In short, the animal is defined by lacking whatever the human is and has. More recent critical animal studies have tried to reconceptualise this idea of the animal as defined by lack, either by demonstrating that animals do not in fact lack faculties such as language, or conversely by, in Jacques Derrida's phrase, "acceding to a thinking, however fabulous and chimerical it might be, that thinks the absence of the name and of the word otherwise, as something other than a privation" (Derrida 2008, p. 73). Indeed, when Pirkis reaches for a positive description of Brooke, the image is again animalistic: "her one noticeable trait was a habit she had, when absorbed in thought, of dropping her eyelids over her eyes till only a line of eyeball showed, and she appeared to be looking out at the world through a slit, instead of through a window" (Pirkis 1894, p. 6), an image of both feline habit and of captivity.

In 'The Murder at Troyte's Hill,' Brooke's animality is highlighted in the scene where Brooke discovers the body of Captain. Searching the house and grounds for clues, Loveday enters the somewhat chaotically organised gardens, and finds the dog in the belt of shrubbery and trees near the lodge:

A bird flew from out the thicket on her right hand with a startled cry. A dainty little frog leaped out of her way into the shrivelled leaves lying below the laurels. Following the movement of this frog, her eye was caught by something black and solid among those leaves. What was it? A bundle-a shiny black coat? Loveday knelt down, and using her hands to assist her eyes, found that they came into contact with the dead, stiffened body of a beautiful black retriever. She parted, as well as she was able, the lower boughs of the evergreens, and 
minutely examined the poor animal. Its eyes were still open, though glazed and bleared, and its death had, undoubtedly been caused by the blow of some blunt, heavy instrument, for on one side its skull was almost battered in (Pirkis 1894, p. 72).

An Edenic space of ornamental animality (a 'dainty little frog') is immediately undermined by the invocation of Darwinian realities. Pirkis's thicket recalls Darwin's entangled bank, the image that closes The Origin of Species (1859), another space subject to investigative inquiry ("It would be interesting to contemplate an entangled bank, clothed with many plants of many kinds, with birds singing on the bushes, with various insects flitting about ... " (Darwin 1985, p. 459)). Pirkis' image of pastoral animal harmony quickly becomes more Darwinian than Edenic, glancing at the shrivelled leaves that have lost out to the laurels. Loveday observes that the manner of the dog's death perfectly matches that of Sandy's. Yet rather than presenting a scene of human authority over nature, Brooke must not only follow animal signals in making her discovery, but become animalistic herself. Brooke is alerted to the presence of Captain's corpse by watching the leaping frog; as she enters the thicket, Brooke's detection is forced to become haptic rather than optical ('using her hands to assist her eyes'), challenging a humanist primacy of vision most notably established by Freud in Civilization and its Discontents, whereby animalistic senses of smell and touch are developmentally replaced by sight (Freud 1991, p. 288). ${ }^{2}$ As Rohman notes, touch "is perhaps the least linear sense; it is of multiplicity rather than identity, the sensory experience of otherness and difference ... . Touch emphasizes our corporeality" (Rohman 2009, p. 110). Brooke parts the boughs 'as well as she was able'; this is no space of human mastery. Rather, the first of the story's crime scenes resembles Haraway's contact zone. Identities are dialectically renegotiated: Captain, in being found murdered in the same manner as Sandy (rather than simply dying), gains a status usually reserved for the human, while Loveday must become animalistic to make the discovery.

As Hendrey-Seabrook points out, the naming of the series as 'Experiences' rather than the more usual 'Adventures' foregrounds the acquisition of knowledge, having the scientific etymology of 'having been put to the test' (Hendrey-Seabrook 2008, p. 79). Hendrey-Seabrook goes on to argue that Pirkis is attempting to "authorize her heroine's activities through alignment with a scientific, experiential discourse" (ibid., p. 79), but this argument needs more precision; after all, the term 'experience' also foregrounds bodily sensation, empathy, and compassion (as Gavin notes, the term situates Brooke's cases "in her lived, working experience and implies the professional authority and wisdom that she has gained. Adventures are also often shared, while experiences are more subjectively individual" (Gavin 2010, p. 148)). Clearly, for Pirkis, not all scientific discourses are equal, and while the detective may be the instrument of emotional cruelty (exposing secrets which others would have remain concealed), Brooke stands against investigations which rely on physical cruelty, and the category errors that arise from vivisectionist discourse. Craven's scientific obsessions and lack of wider perception beyond his philological work (he forgets who Brooke is at several points, has little memory of events, and complains at breakfast that "the cups and saucers distract me" (Pirkis 1894, p. 76)) parody the vivisectionist as described by the French experimental physiologist Claude Bernard in his Introduction a l'Etude de la Medicine Experimentale (1865):

He is no ordinary man. He is a learned man, a man possessed and absorbed by a scientific idea. He does not hear the animals' cries of pain. He is blind to the blood that flows. He sees

2 Carey Wolfe and Jonathan Elmer note how that, for Freud, "the human animal becomes the one who essentially sees rather than smells" (Wolfe and Elmer 1995, p. 156). Kari Weil sees the primacy of vision in Derrida's The Animal That Therefore I Am, with its famous scene of Derrida being observed naked by his cat, as a conceptual problem in Derrida's challenge to phallogocentrism and anthropocentrism: "[T]o focus on the gaze of an animal and especially on that of an animal who looks at me is to remain within a humanistic tradition that values sight above all other senses and that identifies seeing with knowing. We look at their look to see what they tell us about ourselves, what they see in us. This is anthropocentrism of another kind-one that critiques who is doing the picturing, but not the act of picturing itself" (Weil 2012, p. 45). 
nothing but his idea, and organisms which conceal from him the secrets he is resolved to discover (Cobbe 1882, p. 18).

Cobbe, quoting this passage in her anti-vivisectionist treatise The Higher Expediency, aligned such an image with that of the murderer: "it is, to my thinking, an awful picture of a man besotted with lust of knowledge, just as murderers are sometimes besotted with lust of gold" (Cobbe 1882, p. 18). Pirkis, however, takes Cobbe's conception of the experimental physiologist one step further; whereas for Bernard the cries of the animal are irrelevant, in Craven's work the cries are central; in the move from experimental physiology to experimental philology, pain becomes not incidental but central.

The deaths of Sandy and Captain turn the singular murder of the story's title into an accusation: is it only Sandy's death that counts as a murder, despite both acts being carried out from similar motives? In an earlier Pirkis story which explicitly addresses vivisection, 'Jack-A Mendicant' (1881) (published in Belgravia and subsequently reprinted by the Anti-Vivisection Society as a pamphlet), Pirkis leaves no doubt that the deaths of animals from experimental physiology are moral, if not legal, murders. The story's blind central character, Caleb, loses his family to fever and consumption, and is reduced to begging. Caleb's only companion is a terrier, Jack, who gives his life affective meaning in the face of an economic and social uselessness, and indeed much of the story is concerned with addressing prejudices about working-class interactions with animals, the kinds of interactions most closely policed by the nineteenth century RSPCA (as the narrator notes, "poor people are not always thrashing horses and kicking dogs to death, as some think" (Pirkis 1881, p. 59)). Jack and Caleb's relationship becomes another Harawayian contact zone of mutual renegotiation, with Caleb sleeping on straw while Jack becomes "very punctual in his habits" (ibid., p. 60). This harmonious cross-species intersubjectivity is interrupted, however, by a violent reassertion of the human/animal hierarchy. When Jack goes missing, Caleb undertakes some brief detective work to trace him to a physiologist's laboratory. Unfortunately, he is too late to prevent a crime; Jack is dead, a victim of experimental physiology. The scientist denies any implication of murder:

A dog, did you say-white haired - thin! Oh yes, I had him with two colleys yesterday afternoon; the brute! He wasn't worth the money I paid for him; he howled so, we had to cut his windpipe before we could do anything with him. I wouldn't have had him if I could have got a third colley: they are so much more quiet and patient. Villain! did you say, old man? No, I'm a physiologist-you shouldn't be abusive; the law protects me, and we must have subjects. (ibid., p. 63).

As leading anti-vivisectionists such as Cobbe had argued, the physiologist's moral sensibilities have become weakened to the extent that an animal life is seen as being of none but economic value. This is not just scientific cruelty, but purely criminal cruelty. Pirkis carries across this excess to the startlingly graphic (for the Belgravia) description of Jack's corpse:

Caleb took the mangled body of his old friend reverently into his arms, he passed his hand tenderly over the strained eyeballs, the blood-stained throat, the severed ribs. "My God," he said [ ... ] "I can thank Thee now that I have no sight wherewith to see the wickedness these Thy creatures have wrought." (Pirkis 1881, p. 63).

Pirkis is clear that this is a crime scene: Jack has been murdered rather than simply killed, with the physiologist's invocation of a protective human law becoming deeply ironic (likewise, Caleb attempts to break down the boundaries reasserted by the physiologist; like Brooke's animality in finding Captain's body, at this point the narrative of 'Jack-A Mendicant' emphasises Caleb's sense of touch, and he ironically identifies the murderers of the terrier as god's 'creatures'). The final scenes of the story offer a double perspective. On one hand, according to classical philosophy, the animal cannot be murdered (only killed), providing the alibi by which Pirkis presents in Belgravia a visceral scene of death that could not be considered if it had described human murder. But on the other hand, readers are clearly invited to regard Jack's killing as a matter both of horror and of law (the physiologist 
himself makes this point), since Pirkis has narrowed the identificatory distance between the human and the animal.

\section{Animal Voices: The Crisis of Comparative Philology}

Reading 'The Murder at Troyte's Hill' as a satire of vivisection raises a question, however: why should Craven be a philologist rather than a physiologist? Wouldn't Pirkis's point be better made with an explicit scene of scientific experimentation, as in 'Jack-A Mendicant'? An explanation emerges when Craven's research is placed into the later Victorian context of language research, and its implications for the relationship between humans and animals. While in Pirkis's text comparative philology invites comparison with experimental physiology, the latter does not replace or excavate the former, rendering it an empty signifier of amoral experimentation. Rather, readers of the Ludgate Monthly in 1894 may well have recognised comparative philology as embodying anxieties not unrelated to the same questions surrounding vivisection, and with its own investments in the question of the animal. In what follows, then, I build on Hendrey-Seabrook's persuasive argument for the importance of vocality in the Loveday Brooke stories, in which she reads the series through the gender politics of speech and the ways in which Pirkis "makes us alert to Loveday through the way in which she exercises, or chooses not to exercise, her voice .... [Brooke's] style of vocality is not aligned with the femininity of gossip but with the masculinity of resolute pronouncement" (Hendrey-Seabrook 2008, pp. 84, 85). Given this argument, however, it is surprising that Hendrey-Seabrook does not discuss the context of Craven's comparative philological research, an explicit thematisation of voice and its authority, and its relation to the question of the animal.

There is insufficient space to offer a contextual history of the rise of comparative philology in the later nineteenth century, but a brief outline indicates the cultural anxieties associated with the new linguistic science and suggests what is at stake in Pirkis making her villain a philologist. ${ }^{3}$ Craven's work represents the modern outworking of an intellectual genealogy going back to Locke's An Essay Concerning Human Understanding (1690) and the implicit challenge to a theological model of language as divinely inspired; rather than divine gift, language was to be understood in material terms, subject to the same forces as other physical phenomena, an implicitly materialist view more thoroughly worked out in Abbe de Condillac's Essay on the Origin of Human Knowledge (1746). Later eighteenth century linguistic theory backed away from this overtly materialist stance; the crucial text here is Johann Gottfried Herder's On the Origin of Language (1772), a treatise that Linda Dowling argues inaugurated what she terms a Romantic philology underpinned by the concept of language as the voice of a nation or a people, and the main means of disseminating culture and civilization; thus, Herder's theories were developed into Coleridge's lingua communis, a concept which was in turn adopted by the Victorians as the justification for viewing English as "possessing an intrinsic beauty and vital interest all its own" (Dowling 1986, p. 24).

By the mid nineteenth-century, however, the focus of Romantic philology on speech as the 'living breath' (in Herder's phrase (ibid., p. 12)) led to the emergence of a new comparative philology and neogrammarianism which focused on the scientific study of the sounds of language conceived as subject to immutable laws. Associated with continental linguistics, and seeking to distance itself from the earlier conjectural etymologies of Condillac and Lord Monboddo (Ferguson 2006, p. 21), comparative philology was popularised in the mid-nineteenth century by the lectures of Max Müller. Müller emphasised the new science's two underpinning premises: that language was constituted through sound (an inheritance from Herder's focus on the 'living breath' of language as opposed to the deadened written word, an idea itself dating back to Plato's Cratylus), and that it was organised

3 On the cultural implications of comparative philology, see Dowling (1986) and Ferguson (2006); on the development of philology in parallel to reconstructive sciences such as geology (and in turn their relation to detective fiction), see Frank (2003), particularly 9-18. 
according to laws independent of individuals and of representation. These principles, argues Dowling, became "twin foci for Victorian anxieties about the new order of language and the subversion of culture that order seemed to portend" (ibid., p. 62). Put briefly, if for Romantic philologists the English language had been conceived as a vehicle for the dissemination of the values of culture (in the Arnoldian sense) and civilization-the language of Shakespeare and Milton, as opposed to the savage tongue - then the reduction of language to a set of operations determined by immutable laws severed language from such lofty cultural purposes. Likewise, the emphasis on speech acts not only destabilised the written word (as Dowling notes, comparative philology "demonstrated that the apparent stability of the written word was illusory: orthographical conventions varied wildly, a single letter could mask a number of entirely different sounds, and so on" (ibid., p. 64)), but also challenged the discourse of literature as a civilizing and specialised language. To the comparative philologist, the speech of the peasant was of equal value to that of the poet. In Dowling's analysis, the cultural dissolution threatened by the implications of comparative philology gave rise to literary decadence, but as the example of Pirkis demonstrates, such debates also shaped more bourgeois popular fiction.

Where, then, does the figure of the animal enter this trajectory? The animal was never far away from Romantic and Victorian discussions of language, not least because of the longstanding philosophical question of whether the animal could be said to have language. For his part, Müller was explicit that "the one great barrier between the brute and man is Language. Man speaks, and no brute has ever uttered a word. Language is our Rubicon, and no brute will dare to cross it" (quoted in Ferguson 2006, p. 1), although as Christine Ferguson points out, Müller's language foregrounds animal intention rather than incapability (ibid., p. 1). Ferguson characterises Müller (and similar anti-evolutionary philologists such as Ludwig Noiré) as invested in anthropocentric progressionism, arguing that while language may have originated as animal cries, it had developed to become uniquely human (ibid., pp. 2-3). Since, as Ferguson notes, a range of evolutionary thinkers (including Spencer, Romanes, Tylor and Lubbock) agreed "that language was the sin qua non of human identity" (ibid., p. 21), a more divisive question was the issue of how language was to be conceived in terms of animal inheritance. Robert Chambers, in Vestiges of the Natural History of Creation (1844) had provocatively suggested that speech was an inheritance from an animal state of being, depending solely on the correct physiological arrangement. Darwin, in The Descent of Man (1871), attributed the origins of language to animal imitation of natural sounds, allied with increased mental powers ("may not some unusually wise ape-like animal have imitated the growl of a beast of prey, and thus told his fellow monkeys the nature of the expected danger? This would have been the first step in the formation of a language" (Darwin 2004, p. 110)). Yet rather than having mental power preceding language, Darwin was careful to establish a dialogic relationship between the two: "The mental powers in some early progenitor of man must have been more highly developed than in any existing ape, before even the most imperfect form of speech could have come into use; but we may confidently believe that the continued use and advancement of this power would have reacted on the mind itself, by enabling and encouraging it to carry on long trains of thought" (ibid., p. 110). Darwin thus placed himself in opposition to Müllerian human exceptionalism, disputing Müller's claim that "the use of language implies the power of forming general concepts; and that, as no animals are supposed to possess this power, an impossible barrier is formed between them and man" (ibid., p. 111). Much of chapter three of The Descent of Man demonstrates the mental powers of animals, their ability to form general concepts, and the formation of language at the intersection of physiology, imitation and intellect. As already noted, Darwin expanded on this topic in The Expression of the Emotions in Man and Animals, exploring the non-verbal languages of animality in addition to vocal expression.

Expression of the Emotions was revised for a second edition in 1890, by which point philologists had learned the Darwinian lesson and accepted that animals possessed language and turned to investigate the conditions of human-animal communication. H. Carrington Bolton's The Language Used in Talking to Domestic Animals (1897) argued that the language used by humans to address and control the behaviour of animals was a hybrid third form, lacking the grammar of human language but more than 
a mere imitation of animal speech (Bolton 1897, p. 5). As such, this language required an expansion of Alexander Melville Bell's 1867 system of 'visible speech', "a system of notation by which it is possible to represent in ink, on paper, any sound of which the human voice is capable" (ibid., p. 10). While Bolton's project represented an expansion of philological sounds rather than (as in Craven's research) a reduction of them to seven or so fundamental elements, Bolton's work parallels Craven's in one regard: that the dog was a linguistically privileged animal, Bolton suggesting that "Man pays an unconscious tribute to the intelligence of his faithful companion, the dog, by addressing him with words of ordinary speech" (ibid., p. 6). It is this domesticated privilege that leads Craven to his useless experiment on Captain, believing that the intelligence of the dog in addition to the training bestowed on Captain will allow for the utterance of a sound fundamental to both human and animal.

In Experiences, Pirkis largely sidesteps the specific question of whether animals possess language, primarily because her concern is not with the validity of Craven's hypothesis but rather with the ethics of his research. As Linda Dowling notes, the cultural distrust of comparative philology partially arose from the sense that the new linguistic science destructively reduced wholes to parts, and in so doing killed or obscured the subject under examination. Dowling notes that "[Late] Victorians could recall that when [the etymologist Richard Chevenix] Trench analysed words, he exposed to their view the beautiful thoughts and images, the imagination and feeling of past ages those words recorded. When the linguistic scientist anatomized words, on the other hand, he reduced them to such unimaginably bare linguistic particles as the Indo-European roots $\bar{\imath}$ and $a s^{\prime \prime}$ (Dowling 1986, p. 62, emphasis added). The comparative philologist acted in the popular imagination as a linguistic vivisector, disavowing the idea that that language could serve a civilizing or moral purpose, and paying attention solely to the material workings of words, anatomizing and dissecting with no regard to what might be destroyed in the process. Just as Cobbe had condemned Claude Bernard as the scientific criminal focused only on the object of enquiry at the expense of moral and ethical concerns, Dowling suggests that there was a late Victorian distrust of comparative philology as a science that while making "language visible, it simultaneously made language opaque - that is, it taught students to see in language elements-roots, affixes, and so on-that referred to nothing outside the linguistic enquiry" (Dowling 1986, p. 62). Unsurprisingly, then, both pro- and anti-vivisection writers deployed the figure of the philologist as a rhetorical parallel to the vivisector. Edmund Gurney compared experimental physiology and philology in 'A Chapter in the Ethics of Pain' (1881):

The sort of stimulus to pathological science, derived, e.g., from mastery of the mechanism of inflammation, might be compared to the effect on philology, in its early days, of a trouvaille of inscriptions in some unfamiliar dialect. To the outsider either event is barren of meaning; to the expert each is replete with promise, not of some single separate application, but of gradual amplification and modification of the grammar of his subject, and so of further command over all it embraces, through points of fusion with other knowledge which the philologist even less than the pathologist may be able to particularise beforehand. (Gurney 1881, p. 795).

Vernon Lee used a similar image in her defence of vivisection in 1882, arguing that the claims of the experimental physiologist were subject to the same standards of truth as "the assertion of the chemist concerning the property of an element, of the philologist upon a phonetic change, or the historian upon some point of past events" (Lee 1882, p. 792). The most famous statement of the parallel, however, was that by the French ethnologist and philologist Ernest Renan, in his 1882 Sorbonne lecture "What is a Nation?' Challenging Romantic notions of the identification of nation with language, Renan commented that 'It is a delicate thing that I propose to do here, somewhat akin to vivisection; I am going to treat the living much as one ordinarily treats the dead" (Renan 1996, p. 41).

While Christine Ferguson has questioned Dowling's argument that the implications of the new comparative philology were necessarily met with cultural anxiety (arguing that fin de siècle popular fiction often saw the separation of language from national culture as an opportunity for regeneration (Ferguson 2006, p. 6)), Pirkis' association of comparative philology with animal experimentation places The Experiences of Loveday Brooke squarely within the more conservative reaction to the implications 
of Müller's arguments. In this regard, Loveday's assumed position as amanuensis takes on new significance. If one of the cultural anxieties surrounding comparative philology was its destabilising and deadening of the written word as opposed to living speech, then Loveday's role becomes strikingly anti-philological, charged with transcribing Craven's speech into precisely this deadened writing. Yet having hired Brooke to transform his speech into words, Craven baulks at the process: the three scenes of philological work in 'The Murder at Troyte's Hill' are all marked by their failures. In the first, all Craven is able to do is to repeat "the title of his learned work, then its sub-division, then the number and heading of the chapter that was at present engaging his attention"; he then becomes consumed by his attention on the intractable problem of fundamental sounds, and "although Loveday remained seated in that study from early morning till daylight began to fade, she had not ten sentences to show for her day's work as amanuensis" (Pirkis 1894, pp. 77-78). The next day is even less successful: "For fully an hour ... she sat at the writing table with her pen in her hand, ready to transcribe Mr Craven's inspirations. Beyond, however, the phrase, muttered with closed eyes- 'It's all here, in my brain, but I can't put it into words'-not a half-syllable escaped his lips" (ibid., p. 80). Craven ironically becomes dangerously close to Müller's conception of the animal, the dumb beast that dare not speak. In the final scene in Craven's study, the dictation of the work is ultimately side-tracked by Brooke extracting the confession of murder, following which his arrest presumably ends his project altogether.

Craven's attempt to locate a linguistic key to all mythologies leads Joseph Kestner to tentatively suggest that 'The Murder at Troyte's Hill' invites intertextual comparison with George Eliot's Middlemarch (1871), drawing a parallel between Loveday and Dorothea Brooke: both "strive to remedy difficult cases of hardship, at the same time attempting an independence" (Kestner 2003, p. 76). Such a parallel only goes so far, however, since (as Kestner notes) Dorothea's subsuming of her independence into marriage to Lydgate contrasts with Loveday's spinsterhood. However, a more illuminating intertextual parallel, and one which integrates the story's concerns with animality and voice, is Edgar Allan Poe's 'The Murders in the Rue Morgue' (1841). Both stories turn on an investigation into animal speech, albeit one by the detective (Poe) and another by the murderer (Pirkis). In Poe's story, Dupin solves the mystery through the crucial clue of the testimony of various aural witnesses to the event, who insist on the differing accent of the perpetrator, a voice Dupin describes as "that very peculiar shrill (or harsh) and unequal voice, about whose nationality no two persons could be found to agree, and in whose utterance no syllabification could be detected" (Poe 1992, p. 495). The Ourang-Outang presents the kind of pre-human utterance (emphasised in Lord Monboddo's pseudo-etymology of Ourang-Outang as meaning 'Wild Man of the Woods,' a shared ancestor, noted in Poe's story via his invocation of Cuvier (Frank 2003, pp. 36-40)), an elemental sound on which Craven has staked his philological project, and which he fails to find.

Indeed, given these thematic similarities it is difficult not to read passages of 'The Murder at Troyte's Hill' as direct rewritings of Poe, particularly since Pirkis herself was attuned to the poetics of quotation and plagiarism (having claimed that Maxwell Gray's The Silence of Dean Maitland (1886) reworked material from her own Judith Wynne (1884), and accusing the playwright T. Malcolm Watson of copying the title of one of her novels (Gavin 2012, pp. 142-43)). In 'The Murders in the Rue Morgue', the rooms of Madame L'Espanaye are found in a state of disarray:

The apartment was in the wildest disorder-the furniture broken and thrown about in all directions. There was only one bedstead; and from this the bed had been removed, and thrown into the middle of the floor. On a chair lay a razor, besmeared with blood. On the hearth were two or three long and thick tresses of gray human hair, also dabbled with blood, and seeming to have been pulled out by the roots. Upon the floor were found four Napoleons, an ear-ring of topaz, three large silver spoons, three smaller of metal d'Alger, and two bags, containing nearly four thousand francs in gold. The drawers of a bureau, which stood in one corner, were open, and had been, apparently, rifled, although many articles still remained in them. A small iron safe was discovered under the bed (not the bedstead). It was 
open, with the key still in the door. It had no contents beyond a few old letters, and other papers of little consequence. (Poe 1992, p. 481).

Compare, in Pirkis, with the account of the crime scene at Sandy's lodge:

The room, on being entered, presented a curious appearance. It was as if a herd of monkeys had been turned into it and allowed to work their impish will. Not an article of furniture remained in its place: the bedclothes had been rolled into a bundle and stuffed into the chimney; the bedstead - a small iron one-lay on its side; the one chair in the room stood on the top of the table; fender and fire-irons lay across the washstand, whose basin was to be found in a farther corner, holding bolster and pillow. The clock stood on its head in the middle of the mantelpiece; and the small vases and ornaments, which flanked it on either side, were walking, as it were, in a straight line towards the door. The old man's clothes had been rolled into a ball and thrown on the top of a high cupboard in which he kept his savings and whatever valuables he had. This cupboard, however, had not been meddled with, and its contents remained intact, so it was evident that robbery was not the motive for the crime. (Pirkis 1894, pp. 49-50).

Pirkis adopts Poe's narrative trajectory of moving from the wider disarray of furniture, focusing on the bedstead, to a focus on the contents of receptacles (although Pirkis' is full as opposed to Poe's being nearly empty), via a disavowal of robbery as a motive for crime. The detective Griffiths even asks Brooke "what this scene of confusion recalls to your mind before anything else?" (Pirkis 1894, p. 62), pointing to the scene's status as facsimile (at the level of plot, Brooke's answer of "The room of an unpopular Oxford freshman after a raid upon it by undergrads" (ibid., pp. 62-3) facilitates the subplot regarding Craven's son, but at the level of text the same question asked of the reader invites Poe as the answer). The clinching detail, however, is Pirkis' invocation of a hypothetical 'herd of monkeys' as the cause of the disorder, recalling the Ourang-Outang of Poe's tale (the 'as if' of Pirkis's phrasing implying an alternative narrative, literally so for the reader in the case of Poe's intertext). The attribution of "impish will' to animals is likewise a philosophically provocative move; contrast this with the police's speculation that the disorder might have been caused by a lunatic human (just as the narrator of Poe's story suspects that 'A madman ... has done this deed" (Poe 1992, p. 497)), who carries out the destruction not according to will, but to his 'frenzy' (Pirkis 1894, p. 56)). Indeed, as Poe's Ourang-Outang commits the murders through an instinct to copy ("Razor in hand, and fully lathered, it was sitting before a looking-glass, attempting the operation of shaving, in which it had no doubt previously watched its master. [ ... ] the gigantic animal had seized Madame L'Espanaye by the hair ... and was flourishing the razor about her face, in imitation of the motions of a barber" (Poe 1992, pp. 502-3)), Pirkis's aping of Poe brings her close to the status of the Ourang-Outang itself.

\section{Conclusions}

Pirkis' animal advocacy should not be overstated; while an active campaigner for the welfare of animals, and closely connected to various anti-vivisectionist movements, it would be misleading to characterise her as a precursor to later critiques of anthropocentrism informed by poststructuralism. Pirkis' representations of animals remains embedded within a discourse of an identity-based animal rights, which argues for justice for animals on the basis that they can be seen as homogenous with human beings and therefore subject to the same rights (in contrast to more recent critical animal studies based on absolute difference between humans and animals, and where the problem is not how the distinction is erased, but rather how it is complicated and its hierarchy destabilised). Pirkis' animal fictions, from The Experiences of Loveday Brooke, Lady Detective to 'Jack-A Mendicant', focus more on questions of the ethical treatment of an other who can only be understood by reference to humanist categories. A succinct way of summarising this would be to say that while for Pirkis' animals can be fully fledged victims of crime, animals are never themselves granted the full subjectivity to become themselves criminal. Yet while I am not claiming Pirkis as a forerunner of more recent critical animal 
studies, I conclude by noting two such theoretical contexts that are suggestive for reading animality in her work.

Surprisingly, given Pirkis' investment in a humanist model of animal rights, the first of these suggestive theoretical parallels is Jacques Derrida's claim in The Animal That Therefore I Am (2008) that the question of the animal is always already the question of crime. In a discussion which, like Pirkis' fiction, is concerned with the unstable division between murder and killing, Derrida suggests that the very idea of a 'question of the animal' represents a kind of intellectual violence inasmuch as one singular term, the 'animal', is used to describe all non-human living creatures:

The confusion of all nonhuman living creatures within the general and common category of the animal is not simply a sin against rigorous thinking, vigilance, lucidity, or empirical authority, it is also a crime. Not a crime against animality, precisely, but a crime of the first order against the animals, against animals. Do we consent to presume that every murder, every transgression of the commandment 'Thou shalt not kill' concerns only man ... and that, in sum, there are crimes only 'against humanity?' (Derrida 2008, p. 48).

The very term 'animal', for Derrida, already implies the priority of the human: "Animal is a word that men have given themselves the right to give" (ibid., p. 32). Likewise, it is humans who decide what constitutes murder, and who and what is 'killable'; in most cases, humans are murdered, but animals are merely killed. Pirkis tackles this question directly; not only is it criminal to talk of the animal in the singular, and to assume that murder is that which is proper to the human, but where detective fiction becomes involved with questions of murder, it also implicitly addresses the question of the animal. Reading Pirkis' work alongside this Derridean argument offers a twofold perspective. Firstly, it should alert us to the (often fleeting) presence of the animal in Victorian and Edwardian crime fiction more broadly; the figure is, of course, inescapable in a novel like The Hound of Baskervilles (1902), but less obvious in one like A Study in Scarlet (1887), until we realise that the murders of that novel cannot occur without the aid of the horses who pull Jefferson Hope's cab. Secondly, through stories such as 'Jack-A Mendicant', Pirkis demonstrates that to write animal fiction is also, inevitably, to write crime fiction.

The second theoretical context is both more apocalyptic and specific to Pirkis, suggested as it is by the etymology of Loveday's first name. Hendrey-Seabrook notes that 'Loveday' refers to "the medieval custom of appointing a specific day to settle disputes and refers to the reconciliation reached on that day" (Hendrey-Seabrook 2008, p. 77). The obvious reading is of the reconciliatory function of the detective; Loveday resolves mysteries and brings order where there has been disruption. But I also wonder if there is a more apocalyptic context here; Loveday, the day of reconciliation, as also the day of judgement. After all, one of the Brooke stories ('The Ghost of Fountain Lane') centres on a Millenarian cult at which one of the preachers gives a sermon on the battle of Armageddon, featuring "the birds of prey [coming] from all quarters, and the stealthy tigers and leopards creeping out from their mountain lairs" (Pirkis 1894, p. 264). While Pirkis is broadly sceptical about Millenarianism, this animalistic end of history finds echoes in another source, as recounted in Giorgio Agamben's The Open: Man and Animal (2002). Agamben describes an eschatological scene from a thirteenth-century Hebrew Bible, an image of the messianic banquet of the righteous at the end of time:

Beneath the crowns, the miniaturist has represented the righteous not with human faces, but with unmistakably animal heads. Here, not only do we recognise the eschatological animals in the three figures on the right- - the eagle's fierce beak, the red head of the ox, and the lion's head-but the other two righteous ones in the image also display the grotesque features of an ass and the profile of a leopard. And in turn the two musicians have animal heads as well-in particular the more visible one on the right, who plays a kind of fiddle and shows an inspired monkey's face. (Agamben 2004, p. 2).

Agamben asks: "Why are the representatives of concluded humanity depicted with animal heads?" (ibid., p. 2), before answering his own question: the end of Hebraic history will also be the 
end of the human/animal binarism, and of what Agamben refers to as the anthropological machine that sustains this division: "on the last day, the relations between animals and men will take on a new form, and that man himself will be reconciled with his animal nature" (ibid., p. 2). The question of the animal will no longer be the crime theorised by Derrida; the love-day marks the promised reconciliation between humans and animals.

Funding: This research received no external funding.

Acknowledgments: Many thanks to Neil McCaw at the University of Winchester, and Jennifer Diann Jones at The Writer's Agency UK.

Conflicts of Interest: The author declares no conflict of interest.

\section{References}

Agamben, Giorgio. 2004. The Open: Man and Animal. Translated by Kevin Attell. Stanford: Stanford University Press.

Anonymous. 1894a. Sherlock Holmes as a Bore. Pall Mall Gazette, April 6, p. 4.

Anonymous. 1894b. Literary Notes. Liverpool Mercury, April 4, p. 7.

Anonymous. 1894c. Literature. Dundee Courier and Argus, May 16, p. 4.

Anonymous. 1894d. Our London Letter. Cork Constitution, May 19, p. 5.

Anonymous. n.d. A Burning Question. London: Anti-Vivisection Society.

Blackwell, Elizabeth. 1891. Erroneous Method in Medical Education. London: Women's Printing Society.

Bolton, H. Carrington. 1897. The Language Used in Talking to Domestic Animals. Washington: Judd and Detweiler.

Cobbe, Frances Power. 1882. The Higher Expediency. London: Victoria Street Society.

Darwin, Charles. 1985. The Origin of Species by Means of Natural Selection. London: Penguin.

Darwin, Charles. 2004. The Descent of Man. London: Penguin.

Darwin, Charles. 2009. The Expression of the Emotions in Man and Animals. London: Penguin.

Derrida, Jacques. 2008. The Animal That Therefore I Am. Translated by David Wills. New York: Fordham University Press.

Dowling, Linda. 1986. Language and Decadence at the Victorian Fin de Siecle. Princeton: Princeton University Press. Doyle, Arthur Conan. 1951. The Case-Book of Sherlock Holmes. London: Penguin.

Ferguson, Christine. 2006. Language, Science and Popular Fiction in the Victorian fin de Siècle: The Brutal Tongue. Aldershot: Ashgate.

Frank, Lawrence. 2003. Victorian Detective Fiction and the Nature of Evidence: The Scientific Investigations of Poe, Dickens, and Doyle. Basingtoke: Palgrave.

Freud, Sigmund. 1991. Civilization, Society and Religion. London: Penguin.

Gavin, Adrienne E. 2010. Introduction. C. L. Pirkis. In The Experiences of Loveday Brooke, Lady Detective. London: Chatto and Windus.

Gavin, Adrienne E. 2012. C. L. Pirkis (not 'Miss'): Public Women, Private Lives, and The Experiences of Loveday Brooke, Lady Detective. In Writing Women of the Fin de Siecle: Authors of Change. Edited by Adrienne E. Gavin and Carolyn W. de la Oulton. Basingstoke: Palgrave Macmillan, pp. 137-50.

Gurney, Edmund. 1881. A Chapter in the Ethics of Pain. Fortnightly Review 30: 778-96.

Haraway, Donna. 2008. When Species Meet. Minneapolis: Minnesota University Press.

Hendrey-Seabrook, Therie. 2008. Reclassifying the Female Detective of the Fin de Siecle: Loveday Brooke, Vocation, and Vocality. Clues: A Journal of Detection 26: 75-88. [CrossRef]

Kestner, Joseph. 2003. Sherlock's Sisters: The British Female Detective, 1864-1913. Aldershot: Ashgate.

Lansbury, Coral. 1985. The Old Brown Dog: Women, Workers, and Vivisection in Edwardian England. Madison: Wisconsin University Press.

Lee, Vernon. 1882. Vivisection: An Evolutionist to Evolutionists. Contemporary Review 41: 788-811.

Miller, Elizabeth Carolyn. 2005. Trouble with She-Dicks: Private Eyes and Public Women in the Adventures of Loveday Brooke, Lady Detective. Victorian Literature and Culture 33: 47-65. [CrossRef]

Pirkis, Catherine Louisa. 1881. Jack—A Mendicant. Belgravia 45: 56-64.

Pirkis, Catherine Louisa. 1887. A Dateless Bargain. London: Hurst and Blackett.

Pirkis, Catherine Louisa. 1894. The Experiences of Loveday Brooke, Lady Detective. London: Hutchinson. 
Pittard, Christopher. 2011. Purity and Contamination in Late Victorian Detective Fiction. Farnham: Ashgate.

Poe, Edgar Allan. 1992. The Complete Stories. New York: Alfred A. Knopf.

Renan, Ernest. 1996. What is a Nation? Trans. Martin Thom. In Becoming National: A Reader. Edited by Geoff Eley and Ronald Grigor Suny. Oxford: Oxford University Press, pp. 41-55.

Rohman, Carrie. 2009. Stalking the Subject: Modernism and the Animal. New York: Columbia University Press.

Skaris, Katherine. 2014. Affective Labouring in Catherine L. Pirkis' The Experiences of Loveday Brooke: Lady Detective. The Victorian 2: 1-14.

Weil, Kari. 2012. Thinking Animals: Why Animal Studies Now? New York: Columbia University Press.

Wolfe, Carey, and Jonathan Elmer. 1995. Subject to Sacrifice: Ideology, Psychoanalysis, and the Discourse of Species in Jonathan Demme's. Silence of the Lambs. Boundary 22: 141-70. [CrossRef]

2018 by the author. Licensee MDPI, Basel, Switzerland. This article is an open access article distributed under the terms and conditions of the Creative Commons Attribution (CC BY) license (http://creativecommons.org/licenses/by/4.0/). 